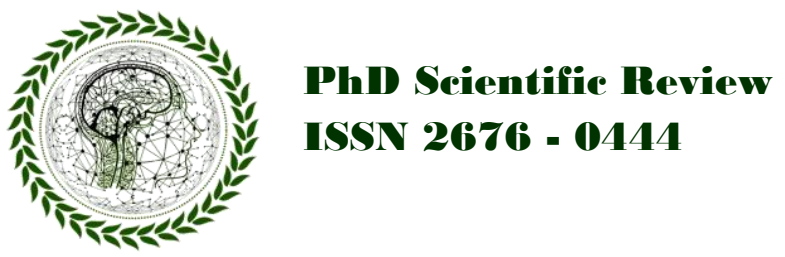

Artigo submetido em: 11/06/2021

Artigo aceito em: 14/06/2021

Artigo publicado em: 24/06/2021

\title{
AS CONTRIBUIÇÕES DO SERVIÇO DE INSPEÇÃO ESCOLAR PARA O DESENVOLVIMENTO DA EDUCAÇÃO BÁSICA
}

\author{
Marcus Antônio Santiago ${ }^{1}$
}

\begin{abstract}
RESUMO
O presente estudo tem por objetivo identificar, abordar e retomar a formação do Inspetor Escolar. Analisar as principais concepções do serviço que norteiam a sua prática diária. Apresentar ações e perspectivas do serviço de modo geral. Discutir a educação com base direcionada para o planejamento, políticas públicas educacionais, gestão e interação com outros grupos dos estabelecimentos de ensino que pertencem a rede de ensino público e privado da Educação Básica. Compreender a estrutura organizacional como possibilidade que favoreça a dinamicidade e comunicação entre os organismos regionais, estaduais da educação e suas unidades escolares. Refletir sobre aspectos sociais, ideológicos, políticos e administrativos que afetam direta e indiretamente a organização e as relações entre comunidade escolar e sociedade. Contextualizar atividades inerentes à função técnica-administrativa-pedagógica do Inspetor Escolar. Rever e propor perspectivas para o trabalho participativo e global dentro do espaço escolar; possibilitando que esse seja um lugar norteado pelos princípios da ética e educação, através de ações concretas que tragam novas abordagens nos processos organizacionais de cada instituição de ensino onde promova a comunicação e respeito entre todos os envolvidos na construção de uma educação de qualidade.
\end{abstract}

Palavras-chave: Inspeção Escolar; Educação; Ações práticas pedagógicas.

\begin{abstract}
:
This study aims to identify, approach and resume the training of the School Inspector. Analyze the main conceptions of the service that guide your daily practice. Present actions and perspectives of the service in general. Discuss education based on planning, public educational policies, management and interaction with other groups of educational institutions that belong to the public and private education network of Basic Education. Understand the organizational structure as a possibility that favors dynamism and communication between regional, state education bodies and their school units. Reflect on social, ideological, political and administrative aspects that directly and indirectly affect the organization and relations between the school community and society. Contextualize activities inherent to the technical-administrative-pedagogical function of the School Inspector. Review and propose perspectives for participatory and global work within the school space; enabling this to be a place guided by the principles of ethics and education, through concrete actions that bring new approaches in the organizational processes of each educational institution where it promotes communication and respect between all involved in the construction of a quality education.
\end{abstract}

Keywords: School Inspection; Education; Pedagogical practical actions.

${ }^{1}$ Professor na rede pública estadual de ensino. Graduado em Filosofia, Pedagogia, Teologia, Educação Física. Pósgraduado em Gestão Escolar, Ciências da Religião, Educação Empreendedora. Especialista em educação básica/supervisor pedagógico. msantibaniz@gmail.com 


\section{INTRODUÇÃO}

Segundo estudos realizados por Gonçalves (2008), sobre planejamento e avaliação educacional, pode-se definir que os estabelecimentos de ensino se estruturam e organizam a partir de princípios elementares que constituem a razão da sua fundação, regimento e projeto político pedagógico no contexto de uma hierarquia. Contudo, essa organização passa por diversas atualizações e mudanças no sistema educacional, enfrentando situações burocráticas, administrativas, pedagógicas que as levam a se adaptarem as novas tendências educacionais.

Desse modo, as mudanças rompem velhos paradigmas e promovem a busca por novos padrões para a solução de desafios. Estes desafios variam de acordo com as demandas de cada época, por exemplo, da formação de professores, planos de carreira, mudanças no direcionamento do ensino, adequação às novas tecnologias que tem ganhado o cenário da educação básica, entre outros.

O ponto principal desse artigo consiste em identificar e compreender qual deve ser a função do especialista em Inspeção Escolar na Educação Básica e, qual deve ser seu papel de estruturador e articulista na ação pedagógica e administrativa tendo horizonte otimizar o funcionamento do estabelecimento de ensino com demais órgãos a ele interligados. E ainda, desenvolver políticas públicas educacionais que contemplem a função burocrática do serviço de inspeção diante dos processos que envolvem o ser humano.

O serviço de Inspeção Escolar liga e congrega o espaço escolar as atividades estruturadas e administrativas das unidades escolares às superintendências regionais de ensino e ao órgão centralizador que são as Secretarias de Estado da Educação. Fato esse que se justifica com a Resolução No. 456/2009, Artigo 3:

A inspeção é o processo pelo qual a administração do ensino assegura a comunicação entre os órgãos centrais, os regionais e as unidades de ensino, tendo em vista a melhoria da educação (MINAS GERAIS, 2009). 
A ação pedagógica do serviço de Inspeção Escolar orienta-se a partir da formação e da preparação para o trabalho dentro das orientações e normas que são direcionadas através dos aspectos pedagógicos, administrativos e organizacionais das Secretarias de Educação. O Inspetor Escolar atua objetivando a mediação de situações cotidianas que envolvam o funcionamento das escolas, vida funcional de servidores, alunos, aplicação de medidas legais que tange ainda a estrutura da Educação Básica e conservação do patrimônio público.

Contudo, o inspetor escolar deve sempre promover e contribuir para que se fortaleça a dimensão da democracia, participação e diálogo nas relações interpessoais para melhor gerenciar as atividades, dividir tarefas e proceder de forma transparente no estabelecimento de regras, normas e busca pela resolução dos problemas através do corporativismo dentro das unidades de ensino.

O estudo, investigação e reflexão da atuação do Inspetor Escolar na atualidade são pontos importantes para a melhoria, eficácia organizacional do ambiente de trabalho, qualidade do trabalho dos profissionais da educação e, sobretudo, no empenho para aplicação de novas perspectivas, competências e habilidades.

\section{DESENVOLVIMENTO}

Possibilitando maior compreensão da função do Inspetor Escolar na educação contemporânea e os desafios da profissão desse profissional na atualidade, buscaremos rever e desenvolver a construção histórica ao longo do tempo e seu papel no contexto social, político, educacional frente ao serviço de inspeção escolar.

O Serviço de Inspeção teve sua origem na época da organização do império, com a Lei Orgânica do Ensino Primário. 
Com a República, surge a Reforma Afonso Pena, de 03 de agosto de 1892, de caráter descentralizador, trazendo sensíveis mudanças e criando profundas inovações criando um Conselho Superior de Educação e a Inspetoria Ambulante para atender às escolas municipais e estaduais.

Durante o período que antecede aos anos de 1920 a 1961, cada Estado brasileiro se organizou de acordo com suas necessidades visando a identidade e organização para o serviço de inspeção escolar. Com o advento de novas determinações do governo, a partir da Lei 4.024/61, todos os estabelecimentos de ensino médio e superior públicos e particulares ficaram sujeitos à inspeção federal.

O Conforme registra Oliveira (2008): “essa integração ao serviço de inspeção federal, tinha por objetivo organizar e reestruturar as atividades escolares do ensino primário e normal da época." Ao Inspetor Escolar cabia conceder autorização, credenciamento e inspecionar as práticas pedagógicas dentro das formalidades legais da educação.

No entanto, com o crescimento dos estabelecimentos de ensino, as atividades do inspetor escolar foram sendo fragmentadas em níveis de ensino, quando ficava a cargo da formação que o professor possuía para desdobrar na função inspetor de alunos, professores, repassar e responsabilizar pelos atos referentes à organização curricular, planejamento e elaboração de conteúdos nas diversas modalidades da ensino, assegurando o desenvolvimento conjunto com a federação, estado e município dentro das formalidades vigentes da educação brasileira.

No decorrer da história, a publicação da Lei 5.692/71 trouxe novas orientações e mudanças significativas para a educação em nível nacional. A primeiras alterações e adaptações ocorreram na reorganização do ensino de $1^{\circ}$ e $2^{\circ}$ graus, atualmente Ensino Fundamental e Médio, com isso houve a necessidade de unir e integralizar estabelecimentos de ensino da rede particular 
a pública, pois o serviço de inspeção escolar de todas as unidades de ensino básico ficava as expensas do Estado.

Em 1975 por extrema necessidade, iniciou-se também amplo debate com vistas a reorganizar o quadro do funcionalismo público para admissão e atuação dos profissionais da Inspeção Escolar nos estabelecimentos de ensino, sobretudo no Estado de Minas Gerais. A atuação do Inspetor Escolar, que parecia sem norte na sua real função, saía da fragmentação e passava a ter destaque na sua constituição enquanto carreira do magistério, associada à gestão da parte burocrática da educação e implicou na seleção de pessoas com formação pertinente para o exercício da inspeção escolar e plano de carreira.

A formação dos especialistas em Educação Básica se dava através do curso de Licenciatura em Pedagogia que possibilitava o acadêmico de se licenciar para atuar na educação infantil, anos iniciais do ensino fundamental, disciplinas didático-pedagógicas do antigo magistério, supervisão pedagógica, orientação escolar, administração e inspeção escolar. Porém, através das atuais exigências e reforma da educação, o curso de Pedagogia passa ter atenção especial possibilitado o acadêmico somente à licenciatura plena na Educação Infantil e anos iniciais do Ensino Fundamental ficando as especializações ao nível de pós-graduação Lato Sensu para atuar em atividades de coordenação, supervisão, orientação, administração e inspeção escolar. Registra a LDB 9.394/96, no artigo 64:

A formação dos profissionais da educação básica para administração, planejamento, inspeção, supervisão e orientação educacional para a educação básica será feita em cursos de graduação em pedagogia ou em nível de pós-graduação, a critério da instituição de ensino, nesta formação, a base comum nacional. (BRASIL, 1996)

Inúmeras são as normas que regulamentam a atuação do Inspetor Escolar dentro do estabelecimento de ensino. E a frequente visita desse especialista visa atender dificuldades e normatização das leis educacionais do sistema como um todo. Pois a educação é regida pelas 
normas e orientações do Conselho Nacional e Estadual de Educação (CNE/CEE) e Secretaria de Estadual da Educação (SEE) que são repassadas para os superintendentes e diretores de ensino que devem promover a unidade dos atos administrativos entre os estabelecimentos escolares.

A atuação do Inspetor é mediatizar as relações dos sistemas educacionais em nível local, regional e estadual. Está atuação nos estabelecimentos, objetiva suporte técnico-administrativo e pedagógico dentro das necessidades da instituição de forma ampla e abrangente. Por se tratar de um serviço que não está restrito a sala de aula propriamente dita, esse se desenvolve na organização administrativa das escolas.

Com efeito, o acompanhamento, supervisão, coordenação, orientação e avaliação do serviço de inspeção escolar para surtir os efeitos contínuos nas atividades de rotina diária deve se realizar em equipe, entre os especialistas da área, funcionários das superintendências de ensino e das unidades de ensino. Nesse sentido, Silva (2008) reafirma a necessidade da união em todos os segmentos que tange a organização escolar.

\footnotetext{
Uma organização funciona através da cooperação. União, conhecimento da realidade e o aprendizado contínuo para a solução dos problemas de todos os envolvidos no sistema educacional, escola, professores, especialistas, família, sociedade e, sobretudo o aluno. (SILVA, 2008, p.05).
}

A necessidade do envolvimento dos grupos nas diversas ações pedagógicas somente se consolidará no trabalho ético e em conjunto com o objetivo do cumprimento efetivo das metas estabelecidas pelas secretarias de estado da educação.

Como características do século 21, mediante aos efeitos da pós-modernidade o serviço de Inspeção Escolar também atravessa desafios de romper com velhos paradigmas e renovar sua atuação como atividade que busca articular e renovar meios que favoreçam inclusão e desenvolvimento global da educação. O inspetor escolar desse novo limiar deverá buscar o melhor desempenho para o progresso e verificação das ações administrativas e pedagógicas do 
espaço escolar que a cada dia se encontra fragmentado, promovendo ações concretas, que pautem pela ética, democracia, autonomia e responsabilidade.

O contexto atual de novas linguagens, códigos e tecnologias deve possibilitar que o inspetor escolar envolva-se com as atuais necessidades da comunidade escolar, regional e local acompanhando e executando suas ações por meio de visitas as unidades de ensino, orientando gestores, especialistas em educação básica, funcionários ligados à administração escolar e membros do colegiado na tomada de decisões e na gestão participativa.

A ação pedagógica do inspetor escolar nas escolas hoje deve possibilitar maior interação dos funcionários da escola no regime de colaboração, sobretudo, da gestão escolar. Segundo Silva (2008):

\footnotetext{
Os gestores em educação precisam estar abertos à participação, às mudanças, às novidades e ao diálogo. O comprometimento do líder e a vontade de envolver toda a comunidade escolar são decisivos. Quando isso acontece, estabelece-se uma forte coesão em equipe escolar. Nas instituições escolares, onde os líderes-gestores demonstram confiança na equipe de funcionários, de professores e especialistas, o desempenho é significativo e o sucesso é de todos. (SILVA, 2008, p.58).
}

O inspetor escolar nas visitas cotidianas aos estabelecimentos de ensino deve buscar aproximação de secretários, auxiliares de secretaria, técnicos em educação numa busca constante de aprimoramento da função em reuniões, quando necessário, e na revisão da atuação de cada um para que não haja sobrecarga de funções a uma única pessoa. Deve existir plena comunicação entre todos profissionais da escola, principalmente quando na publicação de novas leis, resoluções, decretos, circulares que necessitam de entendimento de todos os funcionários do setor.

Além das orientações, o inspetor escolar buscará promover, auxiliar os especialistas da educação (supervisor pedagógico e orientador educacional) nas suas atividades e implementação e 
direcionamentos nos projetos estruturados, complementares, avaliação, diagnóstico no ensinoaprendizagem e acompanhamentos de docentes nas suas necessidades quando solicitado.

Portanto, se houver boa comunicação entre os setores da escola e da comunidade as atividades serão prazerosas e favorecerão um crescimento profissional para todos.

\section{CONSIDERAÇÕES FINAIS}

A análise e compreensão da área da inspeção escolar possibilitou a reflexão e investigação nas relações profissionais, no contexto do relacionamento social e político das organizações escolares e o papel do profissional do Inspetor Escolar.

Ao término da elaboração desse artigo, fica a gratidão de realizar um curso que dará futuramente base para a atuação na função de Inspeção Escolar, conhecendo com propriedade as bases desse profissional da educação básica, sua história, seus desafios e novos horizontes para se promover sempre uma visão global do espaço escolar interno e externo com o objetivo de se viabilizar a interação entre todos da escola e, sobretudo a autoestima, a ética e companheirismo.

O serviço de Inspeção Escolar possibilita que o profissional conheça outras experiências pedagógicas positivas e oriente as escolas que talvez não esteja tão bem estruturada e organizada para acolher mudanças significativas na comunidade escolar.

Enfim, a ação pedagógica do trabalho do Inspetor Escolar se abre num espaço que anterior a esse estudo parecia-nos somente uma função de cobranças, autoritarismo, distanciamento e burocracia. Contudo, observamos que sua atuação é muito que isso, pois nos tempos modernos, isso vai além de fichas, livros, leis, planos, mas é norteado pelos princípios da educação universal como forma de tornar a vida melhor e ajudar a outros através da reflexão, ação e conhecimento ser pessoas de bem envolvidas com uma educação de qualidade. 


\section{REFERÊNCIAS}

BRASIL. Lei No. 9.394, de 20 de dezembro de 1996: Lei de Diretrizes e Bases da Educação Nacional (LDBEN). Diário Oficial da União, Brasília, Nº. 248, de 23 de dezembro de 1996.

GONÇALVES, Heitor Antônio. Planejamento e avaliação educacional. $1^{a}$ Edição. São João del-Rei: Universidade Federal de São João del-Rei, 2008.

OLIVEIRA, Noely. Guia de Estudo: Práticas Pedagógicas do Inspetor Escolar. Editora Prominas: Coronel Frabriciano, 2008.

MINAS GERAIS. Resolução Nº. 456, de 30 de setembro de 2009: Dispõe sobre a Inspeção Escolar na Educação Básica no Sistema Estadual de Ensino de Minas Gerais. MG $10 / 2009$.

SILVA, Rosana Cristina Ferreira. Políticas Públicas Educacionais. Editora Prominas: Coronel Fabriciano, 2008. 